\title{
MÉTODOS Y CUESTIONES FILOSÓFICAS EN LA ESCUELA DE TRADUCTORES DE TOLEDO
}

\author{
Mariano Brasa Díez \\ Universidad Autónoma de Madrid
}

\section{RESUMEN}

En este trabajo, después de una introducción sobre la España del siglo XII, hago la presentación de la Toledo del renacimiento medieval donde van a trabajar - ien la Escuela de Traductores? - los grandes traductores y de donde van a salir la mayoría de las obras filosóficas, vertidas al latín, de los autores árabes. También hablo de otros caminos, de otras regiones y de otros traductores. Termino con las traducciones alfonsíes y con dos apéndices donde aparecen las obras traducidas por Ibn Daound-Gundisalvo y por Gerardo de Cremona.

Palabras clave: Toledo, Traductores, Gundisalvo, Gerardo de Cremona.

\begin{abstract}
Philosophical questions and method in Toledo Translaters School. In this paper, after a preliminary section on twelfth-century Spain, I will present Medieval Renaissance Toledo where -in the School of Translators - the great translators did their work, and out of which most of the philosophical works by Arab Authors, translated to latin, emerged. I will also talk about other roads, other regions, and other translators. Finally, I will the Alfonsian translations and I will conclude with two appendices showing the works translated by Ibn Daound-Gundisalvo and by Gerardo de Cremona.
\end{abstract}

Key words: Toledo, Translaters School, Gundisalvus, Gerard of Cremona.

\section{INTRODUCCIÓN}

En la España del siglo XII, en el ambiente de la Reconquista delimitada geográficamente de Navarra al Tajo y, cronológicamente por la toma de Toledo en 1085 y de Zaragoza, en 1118, tiene lugar un primer contacto entre las culturas árabe y latina tan duradero como para poderse dar una ósmosis. Este momento representa para el pensamiento latino un giro decisivo en su desarrollo. Esta España en formación ofrece el aspecto de un medio cultural único. Suscita el entusiasmo, en particular entre los recién llegados, que encuentran aquí el modo de apagar su sed de saber y llenar una ignorancia de la que la Europa cristiana había comenzado a dar señales de sensibilidad. Abelardo, sabiendo de la existencia de la Metafísica de Aristóteles, a la que recuerda con nostalgia, deplora con toda su alma que ningún autor latino haya sido capaz de darla a conocer. Adelardo de 
Bath hace observaciones de mal gusto quejándose de la pobreza bibliográfica del mundo cultural latino de su tiempo.

Encontramos también en esta España reconquistada obispos o señores importantes que hicieron frente a la reorganización eclesiástica; repoblaron regiones devastadas; atendieron a las reformas morales; impulsaron los estudios y las relaciones diplomáticas con los jefes de las taifas, los jefes militares cristianos y el papado. Pero para los mozárabes, los judíos o los musulmanes, la conquista constituía una cierta ruptura con su medio científico natural que con anterioridad se extendía desde los Pirineos hasta la India y englobaba todo el norte de África, Egipto y el Oriente Medio. ${ }^{1}$ Los efectos perniciosos de esta ruptura fueron compensados, mejor o peor, por la gran demanda de sus servicios y de su saber procedentes de los círculos cristianos de la península y, pronto, de Francia y de toda Europa.

Por su intensidad y su radiación, la ósmosis cultural en España hasta el final del siglo XII deja lejos y detrás de sí todos los otros episodios, anteriores y posteriores, de transmisión del saber árabe a Occidente. Su superioridad es debida, primero, al impacto determinante producido sobre el nuevo pensamiento del siglo XII latino por la gran cantidad de obras árabes que, al fin, se convirtieron en algo accesible, y, segundo, por la influencia de ciertas personalidades de primer orden como Juan de Sevilla (Ibn Daoun), Domingo Gundisalvo, Gerardo de Cremona y Hermann de Carinthia. Un detalle nada desdeñable: la Andalucía del siglo XII, a pesar del rigorismo de los almohades, fue el testigo de una actividad cultural muy intensa en filosofía, en ciencias y en letras. Es la época de los Avempace, Ibn Tofayl, Averroes; de los Maimónides, Aboulcassis y Alpetragius. Es también una época de poetas y de místicos.

No tenemos prácticamente ningún vestigio de intercambio científico o filosófico entre latinos y árabes o mozárabes durante todo el siglo XI. Esta época es, sobre todo, la época de la lenta madurez de las peregrinaciones a Santiago de Compostela y de la construción del Camino francés. Por el contrario, resulta curioso señalar que muy pocos de los «letrados» venidos de Francia, monjes, obispos y caballeros, para ayudar a los reyezuelos cristianos en la Reconquista después de la mitad del siglo XI, se mostraron apasionados o atraídos por el trabajo científico. En la España del Cid, los clérigos o letrados franceses se sienten más a gusto en los campos de batalla, frente a los moros, que ocupados en interpretar textos científicos o filosóficos.

\section{TOLEDO, GRAN CIUDAD DEL RENACIMIENTO MEDIEVAL}

De todas las ciudades españolas de la Edad Media fue Toledo, la Tulaytula árabe, la única ciudad conquistada y reconquistada sin violencia. Un historiador árabe, Al-Himyari, en su obra Kitab AlRaud Al-Mitar, (Jardín perfumado) ${ }^{2}$ hace una descripción de la Toledo medieval en estos términos:

1 Recordemos los viajes de Benjamín de Tudela, de Ibn Battuta, del poeta y Sufí Ibn el'Arabi de Murcia e incluso, en el siglo XIV los viajes de Ibn Jaldún. Los musulmanes y judíos de España estaban en contacto directo y constante con todas las partes del imperio árabe, o si se prefiere, con el ambiente cultural del mundo islámico.

2 Abu Abdallah Muhamed Al-Himyari muere en 1494 y es un recopilador árabe que recogió en un repertorio alfabético todas las nociones sobre la península ibérica. Ed. y trad. E. Lévi-Provençal, Leiden, 1938. Trad. esp. M. Pilar Maestro González, Valencia, 1963. 
En Al-Andalus [los árabes entienden por Al-Andalus toda la península ibérica], a setenta y cinco millas de la fortaleza llamada Guadalajara, Toledo es el centro de todo el país de AIAndalus y está a nueve jornadas de Córdoba, de Valencia y de Almería. Toledo es una ciudad de extensión considerable. Está bien fortificada y provista de un hermoso cinturón de montañas y de una sólida ciudadela. Toledo es la capital de los cristianos. Está situada en una posición dominante y su territorio es excelente [...] Durante la conquista de Al-Andalus los árabes encontraron en Toledo objetos preciosos en tal cantidad, que sería casi imposible describirlos [...] Había 170 coronas con perlas y toda clase de piedras preciosas. Encontraron también la mesa de Salomón, hijo de David y estaba tallada en una sola esmeralda. Esta mesa se conserva hoy en la ciudad de Roma.

Cuando Tariq Ben Ziad pasó por Toledo, capital del reino de los godos, la encontró deshabitada, pues sus habitantes habían huido. Estableció allí a los judíos y dejó cierto número de soldados. Habiéndose puesto en camino, en persecución de los fugitivos toledanos, llegó a Guadalajara. Desde allí hizo invadir el país de Galicia. Después volvió a Toledo. Esto sucedió en el año 93 de la Hégira.

El soberano procedía en Toledo al nombramiento de obispos a la cabeza de las diócesis, y allí los reunió en concilio con el fin de consultarlos. Había ochenta obispos para ochenta ciudades del territorio de Al-Andalus, así como Galicia, Tarragona, Cartagena...

Los cristianos nos tomaron Toledo a mediados de Muharram del año 478.

La conquista de Toledo (25 de mayo de 1085) fue un acontecimiento tan importante en la historia que se le puede comparar con la conquista de Constantinopla por los turcos en 1453. Era la primera ciudad conquistada a los árabes después de 374 años de ocupación. La Toledo conquistada fue una ciudad en ruinas, si no monumental, sí política y moralmente. En 1075 fue envenenado en Córdoba al-Ma'mun, ${ }^{3}$ y, después del efímero reinado de su hijo, le sucedió su nieto, el apocado alQadir, cuya ineptitud propició la desintegración de todo lo alcanzado por su abuelo. Acuciado por los suyos, sangrado por Alfonso VI, que pretendía venderle muy cara su ayuda, y perdidas Valencia y Córdoba, el apocado al-Qadir, unas veces en su Alcázar toledano y otras refugiado en Cuenca, pierde los controles de su reino, mientras sus súbditos comienzan una lenta pero inexorable diáspora. ${ }^{4}$

Alfonso VI entraba en una ciudad desmantelada. La dispersión de los habitantes de Toledo comenzó durante el asedio a la ciudad, antes de su conquista definitiva. La mayor parte de los hombres verdaderamente importantes de Toledo se refugiaron en Córdoba o en Sevilla o en Granada, o cruzaron el mar para refugiarse en el norte de África. Los repertorios biográficos han dejado constancia de la labor realizada, tanto en el Occidente como en el Oriente islámico, por hombres de cultura que conservaron orgullosamente su denominación de origen: al-Tulaytuli. ${ }^{5}$

3 De la dinastía Zu Nun, que cuando reinaba en Toledo recibió a Alfonso durante diez meses como huésped, cuando fue vencido y perseguido por su hermano Sancho II, y cuya muerte en el asedio de Zamora hizo volver a Alfonso y lo convirtió en rey de Castilla y León.

4 Cfr: J.A. García-Junceda, «La filosofía hispano-árabe y los manuscritos de Toledo. Una meditación sobre el orígen de la escuela de traductores», Anales del Seminario de Historia de la Filosofia, vol. III, Universidad Complutense, Madrid (1982-83), p. 79.

5 Cfr: Teres, «Le Développement de la civilisation arabe à Tolede», Les Cahiers de Tunisie, vol. XVIII, n. 69-70, pp. 83-86. 
Es verdad que otros intelectuales ilustres permanecieron en la ciudad, como es el caso de Ibn Mutahir, autor de una Historia de los faqies y qadíes. Otros se convirtieron al cristianismo como consecuencia de la ofensiva ideológica lanzada por los cristianos sobre los musulmanes. Sin embargo estas conversiones no deben ser interpretadas, sin más, como actitudes oportunistas, provocadas por el miedo o el deseo de medrar, porque la ofensiva ideológica había comenzado antes de la conquista de Toledo, y coincidió con las inquietudes religiosas provocadas por la intensa actividad intelectual en el mundo musulmán a lo largo del siglo XI, que había creado una profunda desorientación. ${ }^{6}$

A la Toledo islámica sucede una Toledo cristiana, sin olvidar el culto islámico y el uso consuetudinario de la lengua árabe que siguieron mozárabes y mudéjares. Allí mismo, conviviendo con el cristianismo y el islamismo, seguía viva la judería toledana sin perder una ápice de su importancia. ¡Magnífica encrucijada de culturas! «Toledo resistió la africanización y se mantuvo firme a los repetidos ataques almorávides», nos dice Sánchez Albornoz. ${ }^{7}$ Continúa el ilustre polígrafo: «Una complicada red de idas y venidas unió, por tanto, a la España cristiana, y en especial a la ciudad de las tres religiones, ombligo del saber en el extremo occidental de Occidente, con ese Occidente consciente de su ignorancia y ansioso de cultura [...] Hicieron camino los hombres que fueron y vinieron de España a Francia y a la inversa. Por él llegaron a la Península diversos estudiosos europeos ávidos de saber y deseosos de apropiarse el que sabían acumulado al sur del Pirineo».

«Toledo tro es una ciudad cualquiera» dijo en su día el profesor Terés. Capital del antiguo reino visigodo, capital de uno de los más importantes reinos de taifas, donde florecieron las artes y las ciencias, desde el siglo VI era la urbs regia, la civitas regalis. El botín de guerra que obtuvieron los cristianos al conquistar Toledo era todo un filón. Allí estaba parte de la biblioteca del califa cordobés Alakan II; allí los libros que de Oriente trajo el bibliófilo toledano Ibn al-Hanasi; allí la herencia de los antiguos reyes árabes; $\mathrm{y}$ allí estaban también las obras de los pensadores griegos escritas en caracteres árabes.

Si la ciencia de Roma dependió de la de Grecia, si la caída del Imperio romano de Occidente llevó consigo la decadencia y el aislamiento intelectual respecto al imperio del Oriente bizantino, el saber de Occidente se reduce a compendios enciclopédicos que van apareciendo con fines distintos. En el siglo V, en el África romana y ocupada por los vándalos, escribe Marciano Capella su De nuptiis Mercurii et Philologiae; en el VI y en la Italia de los ostrogodos, Boecio traducía y comentaba textos filosóficos y matemáticos de Grecia, escribía sobre teología y se consolaba en la Filosofía; en el siglo VII y en la España de los visigodos, san Isidoro escribía sus Etimologías; y en el VIII, en la Britania de los anglosajones, Beda el Venerable escribía sobre métrica, oratoria, ortografía y ciencias naturales e historia para la formación de sus discípulos. Éstos fueron los maestros y guías intelectuales, a los que hay que añadir san Agustín en los siguientes siglos de la Edad Media.

La erudicción profana de los escolásticos anteriores e inmediatamente posteriores a la conquista de Toledo se reducía al Timeo de Platón, traducido por Calcidio; a los tratados de Lógica de

6 Cfr. García-Junceda, o.c., p. 86.

7 Cfr. C. Sánchez Albornoz, El Islam de España y el Occidente, Madrid, Espasa-Calpe, col. Austral, 1974, pp. 190192. 
Aristóteles traducidos e interpretados por Beocio — primera entrada de Aristóteles en Occidente-; a las compilaciones de Casiodoro, Beda, san Isidoro y Alcuino; algunas obras de Séneca - téngase en cuenta el prestigio del que gozaba Séneca en la Edad Media, al ser considerado discípulo de San Pablo- y a la Isagogé de Porfirio, que suscitó la disputa entre «nominales» y «reales». Con estos materiales se levantó la ciencia de Roscelino, san Anselmo, Guillermo de Champeaux, Hugo de San Víctor, Pedro Abelardo... Dogmáticos y místicos; apologistas y heterodoxos; el púlpito y la cátedra; teología y dialéctica.

\section{2. ¿ESCUELA DE TRADUCTORES?}

Todo el que se interese hoy por el saber árabe en Occidente y en el siglo XII va a encontrarse con la presencia de la famosa leyenda de la «Escuela de Traductores de Toledo», que habría sido fundada, o al menos protegida o favorecida, por el arzobispo Raimundo, entre los años 1124 y 1151. La leyenda se remonta a la erudición de A. Jourdain hacia el año 1820, exactamente en 1819 publica sus Recherches critiques sur les plus anciennes traductions latines d'Aristote, por la admiración que sentía hacia los traductores que trabajaban en torno al arzobispo Raimundo.

Es verdad que desde la Edad Media existe una tradición literaria tendente a exaltar la función de Toledo, después de su reconquista en 1085, como el centro europeo de conocimientos y actividades científicas en contacto con la cultura árabe. Desde los siglos XIII y XIV algunos autores describen España, principalmente Toledo, como la patria de la necromancia, del saber exótico e incluso del saber exotérico. Esta tradición se remonta, al menos, a la época del monje Gerberto, en el siglo X, cuando fue recomendado por el abad de Aurillac al conde Borrell II de Barcelona para que le atendiese durante su estancia en España, donde pretendía ampliar estudios. Corrían los años 967970 .

No vamos a entrar en disquisiciones sobre el término escuela. Es verdad que toda disertación debe comenzar explicando los términos. La «explicatio terminorum» era el punto de partida de los filósofos medievales. Si nos atenemos a lo que el Diccionario de la Real Academia nos dice sobre el término escuela, de las once acepciones que da, tal vez alguna podría ser aplicable a este grupo de intelectuales que trabajaban en Toledo siguiendo un método y un estilo propios. Cuando en 1942 José M. ${ }^{\mathrm{a}}$ Millás Vallicrosa publica Las traducciones orientales en los manuscritos de la Biblioteca de la Catedral de Toledo ${ }^{8}$ después de establecer la continuidad entre la ciencia árabe y la alejandrina, y la vinculación científica de la España musulmana con Bagdad, enumera las primeras traducciones realizadas en España, «anteriores al período áureo de Toledo», y las realizadas en el valle del Ebro en la primera mitad del siglo XII, contemporáneas ya de las llevadas a cabo por el primer grupo de Toledo, donde se encuentra al grupo de traductores más numeroso, cohesionado y perdurable y beneficiado del mecenazgo del arzobispo Raimundo. ${ }^{9}$

8 J.M. ${ }^{a}$ Millás Vallicrosa, Las traducciones orientales en los manuscritos de la Biblioteca de la Catedral de Toledo, Madrid, CSIC, Instituto Arias Montero, Madrid, 1942.

$9 \quad$ Ibídem, p. 9. 
Veinte años después, en 1960, en Nuevos estudios sobre historia de la ciencia española ${ }^{10}$ el gran investigador catalán concluía repitiendo este ceñido bosquejo: «Con estos últimos traductores de que hemos hablado, nos damos ya la mano con el grupo de Toledo, con la llamada "Escuela de Traductores de Toledo", denominada así desde los tiempos de A. Jourdain y de V. Rose, pero que, en rigor, venía a ser un grupo o núcleo semejante a los ya registrados, si bien los superó notablemente, tanto por la densidad como por la continuidad de su producción. En rigor, el grupo o escuela de Toledo marca el cenit de movimiento de las traducciones científicas orientales a la lengua latina»."11

Sánchez Albornoz en El Islam de España y' el Occidente ${ }^{12}$ reconoce que «nunca existió una escuela en el estricto sentido del vocablo, es decir, un cuerpo de traductores organizado y coherente. Toledo fue, sí, el centro principal donde trabajaron hispanos y extranjeros y ese movimiento fue favorecido por D. Raimundo y por alguno de sus sucesores». ${ }^{13}$

Termino este apartado con el testimonio de un especialista, el profesor Juan Vernet, que en su obra La cultura hispano árabe en Oriente y Occidente afirma lo siguiente: «En esa época [s. XII] trabajaron en España numerosos eruditos, buena parte de los cuales se acogieron a la protección del arzobispo Dom Raimundo (1125-1252) y éste pasa por ser el creador de la llamada escuela de traductores de Toledo. En rigor no debiera llamarse escuela, desde el momento en que falta la continuidad y organización del magisterio y que el único vínculo, si lo hay, entre los distintos traductores o grupo de traductores es puramente geográfico y de mecenazgo. Muchos de ellos trabajaron en ciudades muy alejadas de Toledo, y las obras orientales no sólo se tradujeron al latín, sino también al hebreo, poniéndolas al alcance de las escuelas catedralicias y de las sinagogas y pasando, por estas vías, al resto de Europa [...] La identificación de los manuscritos árabes que sirvieron de base a todos estos traductores es, a veces, muy problemática, en especial cuando se trata de las obras de Albumasar o -en el siglo XIII— de Averroes. El estudio comparado de las versiones latinas con sus orientales árabes sólo se ha hecho de modo esporádico hasta ahora. Por otra parte, la producción original de estos traductores es escasa y, cuando existe, se centra en la filosofía o en las ciencias ocultas. Ambas disciplinas no requerían un grado de especialización tan grande como el de las ciencias exactas». ${ }^{14}$

Es verdad que autores como Menéndez Pidal hablan del comienzo en Toledo de una escuela de estudios latino-árabes con mediación hebrea y apoyada por el arzobispo Raimundo. ${ }^{14 \text { bis }}$

10 J.M. ${ }^{\text {a }}$ Millás Vallicrosa, Nuevos estudios sobre historia de la ciencia española, Barcelona, CSIC, Instituto «Luis Vives» de Filosofía, 1960.

11 Ibidem, p. 114.

12 C. Sánchez Albornoz, o.c.

13 Ibidem, p. 193; citado por J.A. García-Junceda, o.c., p. 69.

14 J. Vernet, La cultura hispanoárabe en Oriente y Occidente, Barcelona, Ariel, 1978, pp. 114-115.

14 bis R. Menéndez Pidal, España, eslabón entre la Cristiandad y el Islam, Madrid, Espasa-Calpe, col. Austral, 1956, p. 36. 


\section{LAS TRADUCCIONES TOLEDANAS}

Hablemos de Escuela de Traductores o no, lo cierto es que nos encontramos en Toledo con un grupo de hombres que a lo largo de cincuenta años traducen más de cien obras del árabe al latín.

Si queremos apreciar el valor del aspecto científico y cultural del período en el que estamos inmersos, no tenemos más que comparar el estado del conocimiento del saber árabe en Occidente hacia el año 1100 con el que tendremos a la muerte de Gerardo de Cremona en 1187.

Es verdad que antes de Toledo vamos a encontrar entre los latinos un interés científico en la persona de Pedro Alfonso, judío convertido y bautizado en Huesca en $1106 .{ }^{15}$ Pedro tenía una gran reputación entre sus congéneres, que criticaron su conversión achacándola a «viles motivos». Esto le llevó a escribir sus Dialogi contra Judaeos. Debemos hacer constar que la conversión tuvo lugar en Huesca, cerca de Zaragoza, unos diez años antes de la toma de Zaragoza (1118) y más de 20 años después de la toma de Toledo (1085). Estos datos geográficos tienen su importancia.

En otra región, a unos $90 \mathrm{~km}$ al oeste de Zaragoza, en Tarazona, reconquistada más o menos al mismo tiempo que Zaragoza, un célebre clérigo español, Hugo de Santalla, traducirá al latín más de diez obras científicas árabes, para beneficio del obispo Miguel... Más al oeste, cerca de Logroño y en la misma región del Ebro, los traductores Hermann de Carinthia y Roberto de Retines trabajan juntos en traducciones científicas árabes cuando en 1141 encuentran a Pedro el Venerable en su segundo viaje a España. A estos centros tenemos que añadir Barcelona, donde Platón de Tívoli trabajó después de 1135, y Burgos, donde Gonzalo y Salomón traducen la segunda sección de la Shifa de Avicena. De la región del Ebro; de Huesca a Navarra y de Logroño y Burgos a Barcelona, existe un movimiento importante y preponderante cuya misión es transmitir, mediante la traducción, el saber árabe. Antes que el arzobispo Raimundo se interese por este trabajo había comenzado en otras regiones la actividad traductora.

Establecer una traducción correcta ha sido siempre punto menos que imposible y los traductores y los críticos literarios, al menos desde que tenemos noticia de sus modos de trabajo, han tenido conciencia de ello: del traduttore, traditore. ${ }^{16}$

Al-Jahiz ya hablaba en el siglo X y en Oriente de los traductores: «El traductor, dice, tiene que estar a la altura de lo que traduce, tener la misma ciencia del autor que traduce. Debe conocer perfectamente la lengua de la que traduce y aquella a la cual traduce para ser igual en las dos. Pero cuando lo encontremos veremos que las dos lenguas se atraen, se influyen y se contaminan mutuamente [...] Cuanto más difícil es la ciencia, menos son los que la conocen y tanto más difícil será para el traductor y más fácilmente cometerá errores. Jamás encontraréis un traductor digno de estos

15 Se llamaba Moisés Sefardí. Cfr. L. Poliakov, Histoire de l'Antisemitisme. T. II: De Mahomet aux Marranes, París, 1961, pp. 122, 125.

16 J. Vernet, o.c., p. 85. 
sabios. Esto es lo que decimos en cuanto se refiere a los libros de geometría, astronomía, aritmética y música». ${ }^{17}$ «QQué ocurrirá cuando se trate de libros de religión o de teología?».18

Mosé ben 'Ezra, un judío granadino de mediados del siglo XII, planteándose este mismo problema, lo resuelve contando una anécdota: «Una vez, en los días de mi mocedad y en el país de mi nacimiento, preguntóme uno de los más distinguidos sabios musulmanes — era uno de mis amigos y bienhechores-, muy conocedor de su religión, que le recitara en lengua árabe los diez mandamientos. Yo comprendí su intención, la cual no era otra que rebajar el modo de su expresión. Comprendiéndolo así, le rogué que me recitara la primera azora del Corán en lengua latina —él podía hablar esta lengua y la conocía sólidamente. Así que dicho sabio musulmán probó de traducir aquella azora al latín; su expresión era muy deficiente y desfiguró su belleza. Entonces comprendió el porqué de mi respuesta y no reiteró ya su petición». ${ }^{19}$

Después de lo que acabamos de decir, no resulta fácil adentrarnos en el mundo de la traducción para obtener un texto en otra lengua. ¿Cómo arreglárselas para verter al latín el legado cultural árabe depositado en las bibliotecas toledanas? Hoy la tarea de traducir es y nos la imaginamos muy simple. Cualquiera de nosotros traduce un pasaje del francés, del inglés, del alemán... y lo incorpora a una tesis, a un artículo, a una conferencia..., lo citamos y nuestra misión ha terminado. Otra cosa distinta es cuando se trata de una obra entera. De todas las maneras es una maravilla de nuestros días que una sola persona pueda leer el texto en su lengua original y pueda transcribirlo, sin más, en la lengua en que escribe. Puede servirnos de prejuicio al imaginar las traducciones de los tiempos a los que nos estamos refiriendo, en los que era difícil que se diesen juntos y en una misma persona esos elementos. ¿Qué pasaría, por ejemplo, si quien sabía árabe no sabía leerlo o no sabía latín; si quien sabía leer y escribir latín no sabía árabe o no sabía leerlo?

El análisis crítico de las tempranas traducciones medievales, y hasta el testimonio mismo de los autores, nos revelan los personajes y las lenguas que solían interponerse como intermediarios.

Como un antecedente típico con que comparar lo que diremos de las traducciones toledanas, es conveniente describir, al menos en unos trazos, el procedimiento con el que se llevó a cabo la traducción del Corpus Dionisyacum varios siglos antes, en la época carolingia, cuando el Occidente tuvo un contacto efímero con el Oriente bizantino. En la abadía de San Dionisio, donde se efectúa la traducción del Corpus Dionisyacum, eran tres los personajes que trabajaban en el mismo texto: uno leía el texto griego, otro lo traducía oralmente al latín, y un tercero lo transcribía al latín. Los manuscritos griegos escritos en letra uncial, sin separaciones de palabras y casi ninguna puntuación, dificultaban la lectura, de modo que no todos sabían leerlos. Y, además, el lector estaba expuesto a muchos errores de lectura, como consta de hecho por las obras traducidas. Al lado del lector del texto griego, estaba el oyente traductor al latín, que efectuaba la traducción de viva voz, cuya presencia la constatamos también por los errores, de tipo fonético esta vez y que volvemos a encontrar en las obras traducidas. Pero no terminaba aquí toda la operación. Había que transcribir

17 Yahiz enumera claramente las materias del quadrivium.

18 A. Badawi, La transmission de la philosophie grecque au monde arabe, París, 1968, pp. 21-24, da la traducción francesa de todo el pasaje. Citado en J. Vernet, o.c., pp. 85-86.

19 A. Díez Macho, Mosé ibn 'Ezra como poeta y perceptista, Barcelona, 1953, pp. 14-15. 
y no todos estaban capacitados. Un monje, que sería el oyente-copista, se encargaba de transcribir la traducción latina que oía. El copista puede entender mal, bien sea por mala pronunciación del oyente-traductor, o bien sea por defecto de oído del propio oyente-copista. Nuevos errores venían a sumarse a los anteriores. ${ }^{20}$

Nos encontramos con un texto escrito en lengua griega que debe ser traducido y escrito en latín. Tenemos dos lenguas. En esta labor intervienen tres personajes: lector en alta voz, traductor en alta voz y transcriptor de oído. Las posibilidades de errores son muchas. Pueden darse errores de lectura, de tipo fonético, de traducción, de oído, de transcripción; sin entrar en los errores que podemos llamar externos de los que el traductor es completamente inocente. ${ }^{21}$ El oyente de griego y el locutor en latín era la misma persona. Era el intermediario entre el lector de griego-locutor en griego y el oyente en latín-escritor en latín. Los extremos se unían mediante una persona que se comunicaba con el conocedor del griego y con el de latín. Sería el traductor propiamente dicho porque el tercer personaje se limitaba a poner en latín lo que el oyente en latín le decía.

¿Cómo se traducía en Toledo? Una frase del prólogo del Liber de Anima de Avicena - traducido por Ibn Daound-Gundisalvo - puede ayudarnos a describir el mecanismo de las primeras traduciones toledanas: «[...] Me, [habla Ibn Daound], verba vulgariter proferente, et Domino Archidiacono [referencia a Domingo Gundisalvo, arcediano de Segovia], singula in latinum convertente». Ibn Daound ${ }^{22}$ y Gundisalvo tenían que traducir al latín un texto cuyo original estaba en árabe. Ibn Daound era un judío converso que había vivido en territorio musulmán y en la actualidad era castellano. Conocía el árabe y la lengua romance, pero desconocía el latín. Su compañero Domingo Gundisalvo conocía la lengua romance y el latín, pero desconocía el árabe. El judío converso lee el texto en árabe, lo traduce mentalmente al romance, dicta su traducción al romance y llega hasta los oídos de Gundisalvo, que lo traduce mentalmente al latín y lo transcribe al latín. $^{23}$

El mecanismo de traducción de Toledo es diferente del utilizado en la Alta Edad Media. En los dos casos hay pluralidad de agentes, pero los motivos son diferentes. En la Alta Edad Media por dificultad de lectura, en Toledo por ignorancia de la lengua. Cada vez que nos encontremos con equipos formados por dos personas en las traducciones arábigo-latinas, debemos suponer que el traductor latino ignora la lengua original; es el caso de Gonsalvi-Salomón, trabajando en Burgos.

En la abadía de San Dionisio teníamos tres personajes y dos lenguas: griego y latín. Allí el intermediario era un personaje; aquí el punto de unión es una lengua que está dando sus primeros pasos. No busquemos manuscritos en los que pensemos encontrar las traducciones del árabe al romance. Ahora no, todavía no. Es demasiado pronto. El autor del prólogo del De Anima habla de «verba vulgariter proferente» y no de «verba vulgariter scripta». No encontraremos esas traducciones españolas que sirvieron de intermediarias entre el árabe y el latín. Se las llevó el viento nada

20 Cfr: G. Thery, Tolède grande ville de la Renaissance Médiévale, Orán, 1944, pp. 40-43.

21. Cfr. J. Vernet, o.c., pp. 95-99.

22 Prefiero utilizar este nombre para el compañero de Gundisalvo y no el de Juan de Toledo, Juan de Sevilla, Juan David...

23 Cfr: M. Alonso, «Notas sobre los traductores toledanos Domingo Gundisalvo y Juan Hispano», Al-Andalus, 7 (1943), pp. 155-158; Ch. H. Haskins, The Renaissance of the Twelfth Century, Cambridge, Harvard U.P., 1971. 
más pronunciarlas Ibn Daound. Sólo las recogió su oyente Domingo Gundisalvo que las transfiguró en sus escritos vestidas de latín.

Si en el caso del Corpus Dionisyacum no era fácil destacar la función que cada personaje realizaba, ahora en Toledo es menos complicado. Aquí cada personaje tiene muy bien aprendido su papel y sabe sus limitaciones: el personaje primero (judío) es el lector en voz alta y el traductor oral. Tiene entre sus manos la obra en árabe. El segundo personaje (cristiano) es oyente y traductor mental. De su pluma saldrá la obra en latín. Los errores como en el caso anterior pueden ser muchos: posible error de lectura, inexactitud al traducir al romance, error de oído, inexactitud de traducción al latín, error de escritura... Aquí la traducción a una lengua estaba subordinada a la traducción de la otra.

Las traducciones de este dúo, Ibn Daound-Gundisalvo y su actitud versaron esencialmente, pero no exclusivamente, sobre las obras de Al-Kindi, Al-Farabi, Ibn Sina, Al-Gazali, Costa ben Luca, Ibn Gabirol. Todos estos autores pasan luego a engrosar el caudal de conocimientos en el siglo XIII. Estamos en la Universidad. Estos autores serán luego citados por los maestros universitarios gracias a la labor de unos hombres que se dedicaron a traducir al latín el legado científico y filosófico del mundo árabe y del mundo griego.

Este método de traducción inaugurado por Ibn Daound-Gundisalvo persiste todavía en el siglo XIII. En 1217 encontramos en Toledo a Miguel Escoto dedicado a la traducción de obras árabes. Desconocedor de la lengua y de las ciencias de las que habla, según el testimonio de Roger Bacon ${ }^{24}$ e ignorante de los libros de Aristóteles, según Alberto Magno, ${ }^{25}$ se hace ayudar en sus traducciones, de judíos conocedores del árabe y de la lengua del lugar en que viven. En la obra de Miguel Escoto encontramos el nombre de dos judíos, Abuteus y Andrés, probablemente éste es un judío convertido, porque Andrés no es nombre de judío y judaizante.

En 1230 y con Miguel Escoto aparece en Occidente la obra científica de Aristóteles con comentarios más o menos valiosos. La obra de Aristóteles es magnífica, dice Roger Bacon, pero desgraciadamente las traducciones la deforman; y añade el filósofo franciscano: «si tuviera poder las haría quemar».

Hermann el Alemán firma la primera versión latina del Comentario medio de Averroes sobre la Ética a Nicómaco de Aristóteles en 1240. Su campo de acción eran los textos aristotélicos más desdeñados, la Retórica, la Poética, las Éticas, la Política, y como respecto a estas obras los compendios árabes estaban más extendidos o eran más accesibles que el texto de Aristóteles, puso todo su empeño en estos compendios. ${ }^{26}$ Desconoce el árabe como Gundisalvo y Escoto. Se hace rodear de expertos en la lengua árabe y romance, pero, a diferencia de Gundisalvo y Escoto, encuentra ayuda no entre los judíos, sino entre los musulmanes, verdaderos artífices de sus traducciones: «Sarracenos tenuit secum in Hispania [nos dice Roger Bacon], qui fuerunt in suis translationibus principales.

24 R. Bacon, Opus Maius, ed. S. Jebbs, Londres, 1733; pp. 36-37.

25 Albertus Magnus, Opera, t. II, p. 140: «[...] sed Michael Scotus qui in rei veritate nescivit naturas, nec bene intellexit libros Aristotelis».

26 E. Renan, Averroes et l'Averroisme; trad. esp., Madrid, Libros Hiperión, 1992, p. 152. 
Si hasta ahora hemos hablado de equipos formados por dos o más individuos que tenían un empeño común, poner en latín el original griego o árabe, a partir de ahora vamos a encontrarnos con un solo personaje que va a traducir directamente del árabe. No se ha encontrado todavía el personaje al que pudiéramos llamar colaborador de Gerardo de Cremona, y resulta difícil imaginar que tantas traducciones puedan haber sido hechas por una sola persona.

Natural de Cremona, Gerardo es el más activo colaborador de la Escuela de Traductores de Toledo. Tradujo del árabe al latín numerosas obras de filósofos, médicos, físicos, alquimistas, matemáticos, astrónomos y astrólogos griegos y árabes. Aristóteles y sus comentaristas Alejandro de Afrodisia y Temistio son sus preferidos; pero también Galeno, Arquímides, Euclides y Tolomeo son estudiados por el italiano. ${ }^{27}$

A mediados del siglo XII encontramos en Toledo a Gerardo de Cremona. Poco posterior a Domingo Gundisalvo, coincide con él en la ciudad que había abierto las puertas a todos y a la que iban llegando los estudiosos del Occidente cristiano en busca del saber desconocido. El italiano inaugura un nuevo procedimiento de traducción. No podemos encuadrarlo en ninguno de los grupos anteriores. Traduce solo, con lo cual queda suprimido uno de los personajes que intervenían en el proceso de traducción de Ibn Daound-Gundisalvo, así como la lengua intermediaria. Traduce directamente del árabe, incluso obras ya traducidas por Ibn Daound-Gundisalvo. Gerardo es un arabista y busca el método directo en sus traducciones del árabe.

Pero, además, es un helenista, y esto le lleva a centrar sus preferencias como traductor en obras de autores griegos que habían sido traducidas siglos atrás al árabe a través del siríaco.

Hoy, a la luz de los manuscritos que conocemos y haciendo un análisis literario de sus obras, podemos llegar a una conclusión cierta: si el vocabulario de Gundisalvo proviene del romance, el vocabulario de Gerardo de Cremona proviene del árabe y del griego, y será precisamente el griego el que deje su impronta en sus traducciones. En el caso de las traducciones de Ibn DaoundGundisalvo el romance era necesario para establecer el texto; en el de Gerardo de Cremona será el griego el que establecerá la palabra justa, la versión latina perfecta. En la traducción del De intellectu de Alejandro de Afrodisia, Gerardo tiene ante sus ojos la traducción árabe hecha por Isaac ben Honein y el texto griego del propio Alejandro. Gerardo de Cremona aquí se sirve del texto griego para corregir y comprender el texto árabe y confrontar el texto griego con la traducción árabe de Isaac ben Honein. ${ }^{28}$ ¿Estamos ante el «niciador» de las traducciones críticas?

¿De qué manera influyó el griego en las traducciones hechas por Gerardo de Cremona desde el árabe? ¿Confrontando el texto árabe con el texto original griego? Si Gerardo tenía el texto griego, parece como si le sobrara el texto árabe.

El influjo del griego que aparece en las traducciones hechas por Gerardo de obras griegas vertidas al árabe, debemos explicarlo recurriendo a un esfuerzo del traductor en virtud del cual, y gracias a su conocimiento del griego, el árabe se le volvió transparente, y traspasándolo lograba, como por intuición lingüística, una aproximación con el texto original.

27 Cfr: W. Buchwald, A. Hohlweg y O. Prinz, Dictionaire des auteurs grecs et latins de l'Antiquité et du Moyen Âge, Brepols, 1991.

28 Cfr: G. Thery, o.c., pp. 49-50. 
El proceso en el caso de Gerardo de Cremona sería el siguiente: Personaje cristiano, que es el lector mental del árabe, reconstructor mental del texto griego, traductor mental del texto árabe con influjo griego y transcriptor al latín de lo traducido. Los errores posibles ahora disminuyen pero pueden darse errores de lectura, influjo del griego en la traducción de lo leído en árabe y posible error de escritura...

Este método «crítico» utilizado por Gerardo de Cremona en sus traducciones será continuado por Alfredo de Sareshel, Daniel de Morlay y Alejandro Neckam, tres ingleses que llegan hasta Toledo atraídos por sus reservas culturales y científicas.

\section{LA CORTE DE ALFONSO X EL SABIO}

Roger Bacon expresaba en el siglo XIII el descrédito que por entonces pesaba sobre la lengua latina como lengua científica. Lo escrito en latín valía muy poco, según el franciscano inglés, y había que recurrir a elucubraciones redactadas en otras lenguas, «in linguis alienis», por sabios y paganos musulmanes. Entonces, ¿por qué no admitir la lengua materna como vehículo de ciencia?

En el siglo XIII, en Toledo y en otras ciudades españolas y europeas, se llegó a la época fecunda de las traducciones arábigo-latinas, de las que el propio Bacon se benefició de su literal traducción y a menudo mal latín. En el siglo XIII vamos a asistir a la secularización de la cultura, animada por la gran figura del rey Alfonso X el Sabio, que siente esta tendencia como una imperiosa necesidad. A las traducciones arábigo-latinas a través de la lengua romance sucede la época de traducciones arábigo-españolas. Los traductores toledanos que componían su obra en latín van a traer como consecuencia natural los traductores alfonsíes, que compondrán su obra también en romance. Antes el romance era lengua hablada, «vulgariter proferente», no escrita; ahora será definitiva y aparecerá escrita. La interdependencia de ambos equipos de traductores se observa en casos como el del libro de alquimia atribuido a Hipócrates y traducido èn 1256 por orden del Rey Sabio. De esta obra tenemos tres manuscritos: dos de ellos en latín, conseguidos mediante un texto intermedio en lengua romance, y otro en romance que prescinde ya del paso ulterior al latín.

\subsection{Traducciones alfonsíes}

A la época del arzobispo Raimundo, en el siglo XII, sucede la época de Alfonso X el Sabio, en el siglo XIII. Con el Rey Sabio crece la labor de los traductores y va extendiéndose por las ciudades ganadas a los musulmanes. Existía un buen filón de códices que era necesario dar a conocer, y un buen puñado de hombres capaces de hacerlo mediante la traducción. Había que poner manos a la obra. El rey Alfonso X sabe dirigir y estimular. Se rodea de hombres competentes y reúne en una empresa común a judíos y musulmanes, conversos y cristianos. No existe discriminación de raza o religión. El trabajo es el mismo y el fin también. Se traduce todo. Todo interesa. Si el equipo de Ibn Daound-Gundisalvo había traducido, sobre todo, obras filosóficas de autores árabes y las había vertido al latín sirviéndose de la lengua romance como punto de enlace, Alfonso $\mathrm{X}$ y su equipo traduce, sobre todo, obras científicas y literarias. También religiosas, como el Corán... No desdeña la filosofía y las versiones al castellano naciente de los traductores alfonsíes llegan a los tratados de matemáticas, física, medicina, astronomía, filosofía... 
Estamos en el siglo XIII y ahora ya tenemos redacción romance o en idioma materno. En el siglo XII no podía ser. Era demasiado pronto. El romance era sólo lengua intermedia para llegar a un término. Ahora ella misma es término. Se redacta también en castellano. En un manuscrito del De judiciis astrologiae podemos leer: «Juda filius Mosse [Judá ben Mosé [...] transtulit de Arabico in ydeoma maternum [...]» por orden de Alfonso, rey de Castilla y León... Unas líneas después dice: «[...] Alvarus transtulit de ydeomate materno in latinum». Y en el manuscrito 3065 de la Biblioteca Nacional de Madrid y en castellano leemos lo que sigue: «[...] Jhuda fi de Mosse Alcohen su Alfaqui [...] por mandato del antedicho nuestro señor [...] traslatolo de lengua araviga en castellana» el Libro de los juicios de las estrellas (así traduce el título latino De judiciis astrologiae).

$\mathrm{Si}$ es cierto que el rey Alfonso se servía de colaboradores, también lo es que el propio rey participaba directamente en la dirección y redacción de sus obras: ${ }^{29}$ «el rey don Alfonso fue verdadero autor de la Historia General de España, no ordenada sólo de orden suya». ${ }^{30}$ El rey estaba rodeado de eruditos, pero en nadie renunciaba a la hora del trabajo más delicado, pues la selección de los libros «más verdaderos o meiores», sólo es suya, como suya es también la responsabilidad de «poner todas las fechas señaladas». Y en otro lugar leemos»: «el rey faze un libro, non porque escriba con sus manos [aunque también lo hizo, como hemos visto], mas porque compone las razones d'él, e las enmienda, e endreza, e muestra la manera como se deben fazer». ${ }^{31}$

El rey Alfonso X el Sabio tuvo la preocupación de estar cerca de sus colaboradores y fue característica suya, al decir de su sobrino D. Juan Manuel, el que Alfonso «avia muy gran espacio para estudiar en las materias de que quería componer algunos libros, ca moraba en algunos lugares un año e dos e más, e aun, segunt dicen los que vivían a la su merced, que fablavan con él los que querían, e cuando él quería, e ausí avía espacio d'estudiar en lo quél quería fazer para sí mismo e avun para ver e determinar las cosas de los saberes quél mandaba ordenar a los maestris e a los sabios que trayan para esto en su corte». ${ }^{32}$

A la hora de hablar de los trabajos y de las obras del rey Alfonso $X$, debemos distinguir dos períodos: el primero iría de 1250 a 1260 y el segundo de 1260 en adelante. En el primer período se trabaja siguiendo el modelo ya clásico de las traducciones toledanas y, enlazando con ellos, eso sí, redactando también en romance, como ya vimos en el Libro de los juicios de las estrellas y en 1256 en el Liber Picatrix: «Alphonsus X [...] praecepit [...] de aravico in hispanicum transferri»; y otro manuscrito especifica: «de arabico in hispanicum primum traductus postea in latinum conversus».

En este primer período de la escuela alfonsí y en un principio, las traducciones al «ideoma materno» muchas veces las haría una sola persona, como es el caso de Judá ben Mosé. Sucede lo mismo cuando Fernando de Toledo «trasladó de arávigo en romance» el libro de la Azafea. En este caso el Rey Sabio no quedó satisfecho de la traducción y algunos años después recurre a los tradicionales equipos de dos que se usaban en Toledo. Encontramos equipos formados por Judá Mosca el Menor y el clérigo Garci Pérez, que en 1250 traducen el Lapidario; Judá y Guillermo o Guillén

29 Cfr: A.G. Solalinde, «Intervención de Alfonso en la redacción de sus obras», RFE, (1915).

30 Ibánez de Segovia, marqués de Mondéjar, Memorias históricas del Rei D. Alonso, Madrid, 1777, p. 466.

31 M. Alvar, «Alfonso X; la política y la lengua», $A B C, 4-I V-1984$, p. 47.

32 Crónica abreviada, BNM, ms. 1356, fol. 24r.; Cfr. R. Menéndez-Pidal, «Cómo trabajaron las escuelas alfonsíes», Nueva Revista de Filología Hispánica (1951), 373. 
Arremón en 1256 traducen el Libro de ochava esfera y en 1259 el mismo Judá y Juan Daspa hacen lo propio con el Libro de las Cruces y con el de la Alcora.

En el período anterior a 1260 hombres como Judá ben Mosé o Abraham, que tienen como propias las lenguas orientales, se unen formando pareja de trabajo a los Garci Pérez, Arremón, Daspa o Bernaldo que tienen el castellano como lengua propia.

El segundo período alfonsí es diferente. Ahora vemos más un carácter creador. El rey Alfonso ya no se contenta sólo con dirigir y patrocinar traducciones. Hay que hacer acopio de material para trabajar sobre la Historia y las Crónicas. Nada se inventa. Todo tiene que tener una explicación; por eso y para eso podemos leer en el prólogo a la Crónica General: «[...] nos don Alfonso [...] mandamos ayuntar cuantos libros pudimos àver de historias». ${ }^{33}$ Después viene la relación del material: «[...] escogí dellos los más verdaderos y los meiores que y sope, e fiz ende fazer este libro». ${ }^{34}$

Este segundo período es igualmente el período de las obras originales y personales del rey, las Cantigas, las Crónicas, y también el período de las obras originales de sus colaboradores hechas por encargo del mismo rey: el maestro Roldán escribe en 1276 Tafurerías y el maestro Rabizag en 1277 Quadrante. Además, las obras que se habían traducido antes no podían quedar en estado bruto; había que dividirlas, seccionarlas, capitularlas... y de esto se encargaba otro colaborador del Rey Sabio, Juan de Mesina, que capitulará el Libro de las Cruces «segunt es uso de lo fazer».

\subsection{Literalismo de las traducciones alfonsíes}

En el siglo pasado A. Jourdain puso de manifiesto el valor que las traducciones arábigo-latinas suponían para el estudio de la cultura medieval. A partir de entonces fue creciendo el estudio de esas traducciones, a la vez que se examinaban detenidamente y cada vez con más profundidad, y la importancia que representaban para el conocimiento del pensamiento filosófico y científico de la Edad Media fue en aumento. Es verdad que en las traducciones impera un literalismo servil, un estilo incorrecto y bárbaro, pero no podemos negar que el literalismo es el fruto de un espíritu de fidelidad escrupulosa. Hoy pueden parecernos esas traducciones confusas y bárbaras, a veces ininteligibles, como parecieron a Alberto Magno, a Tomás de Aquino o a Roger Bacon, pero el traductor expresa, casi siempre, plenamente lo que quiere decir. ${ }^{35}$

Por lo que se refiere a los traductores de la corte de Alfonso X el Sabio, tenemos que decir que procuraban traducir los originales árabes con un grado de fidelidad verdaderamente admirable. Ya sabemos que estos traductores cortesanos representan el último, pero el más eficaz y fecundo eslabón de aquella cadena que había comenzado en Toledo hacía un siglo. Si en el XII la curiosidad científica y el mecenazgo cultural era ejercido por prelados como el borgoñes D. Raimundo, ahora, en el siglo XIII, la curiosidad científica, el mecenazgo e incluso el propio trabajo están personificados de manera brillante por el mismo Rey Sabio. La labor de traducción del árabe al naciente castellano está representada por el grupo judío en el que destacan los nombres ya citados de Rabí Zag, Judá ben Mosé, Don Abraham el Alfaqí... Este grupo judío había sido educado en la tradición cultural de la España musulmana y, al traducir al castellano las obras árabes, salva restos de la cultu- 
ra musulmana, precisamente en el momento en el que comenzaba su eclipse de manera definitiva. Fruto del trabajo de este equipo son las traducciones castellanas de obras científicas cuyos originales árabes se han perdido y, también, la traducción de obras árabes al romance y después al latín, como ya hemos visto.

Una vez admitido el hecho de la fidelidad al fondo del original traducido, vamos a detenernos ahora en el grado de literalismo con que se efectúa la traducción. Era difícil para los traductores de la corte de Alfonso X el Sabio verter al castellano, que comenzaba a hacer sus pinitos como lengua, otra lengua tan preparada y educada científicamente como el árabe, que tenía ya su terminología técnica para cada disciplina. Los traductores judíos conocedores del árabe, lengua semita como el hebreo, conocían también el fondo lexicográfico del árabe. Era análogo al hebreo. Había que trabajar sobre una obra escrita no en lengua «materna», aunque análoga a ella, y verter a otra lengua que tampoco era la «materna» y, en este caso, ni siquiera era análoga. El traductor judío se vio obligado a poner en circulación un léxico científico adécuado a las circunstancias. ¿Qué sucede? Pues que, al desconocer las reglas del latín clásico, introduce en sus traducciones una serie de palabras de origen árabe y emplea un sistema de derivación a espaldas del latín. El carácter semítico del original sobre el que trabaja y el original semítico del traductor quedan plasmados en la obra que produce. ${ }^{36}$

Todo este literalismo extremado y estas influencias de la lengua de los traductores judíos que rodeaban al Rey Sabio, son prueba del espíritu de estricta y servil fidelidad con que trataban sus fuentes arábigas. Su labor fue positiva y trascendente. Facilita el manejo directo de toda clase de fuentes y generaliza el desarrollo cultural, no sólo en la corte de Alfonso X el Sabio, sino también en los vecinos países de Europa. Hasta allí llegan las obras en castellano que van a verse traducidas en otras lenguas. Las Tabulae Alphonsi fueron muchas veces impresas, desde la edición de Venecia en 1483 hasta la de Leipzig en 1580. Los científicos las manejaban y el mismo Copérnico en 1500 trabaja sobre las Tabulae alphonsinae y las anota de su puño y letra.

El renacimiento cultural que se pruduce en la Europa del siglo XII hace también acto de presencia en España, y, si los traductores toledanos, patrocinados por un arzobispo borgoñés, llevan sus obras filosóficas y científicas en su latín «bárbaro» a la universidad del siglo XIII, los traductores alfonsíes, impulsados por el rey de Castilla y León, D. Alfonso, siguieron el ejemplo de los toledanos y, contemporáneos de la universidad, en época de profundo afán de saber, que se extiende por todas partes en la segunda mitad del siglo XIII, llevan sus obras científicas en castellano «semitizado» a los científicos que comienzan a preguntarse por una ciencia diferente, por la ciencia de las estrellas, por «saber la anchura dell orient del sol et de su occident, et otrossí de los orientes de las otras estrellas, et de son occidentes, per la linna circular».

\author{
Mariano Brasa Díez \\ Departamento de Filosofía \\ Universidad Autónoma de Madrid \\ Ctra. de Colmenar Viejo \\ E-28049 MADRID
}

36 Cfr: J.M. ${ }^{a}$ Millás Vallicrosa, «El literalismo de los traductores de la corte de Alfonso el Sabio», Al-Andalus (1933), pp. 155-187. 